\title{
SODIUM AMYTAL AND BEHAVIOUR IN NEUROTIC SUBJECTS
}

\author{
BY \\ S. G. LAVERTY and C. M. FRANKS \\ From the Institute of Psychiatry (Maudsley Hospital), University of London
}

Sodium amytal is a barbiturate drug which has been used for some 25 years as a sedative, narcotic, and anticonvulsant. Data concerning its action and the action of structurally similar moderateduration barbiturates such as "dial" and " nembutal ", suggest that it has both central and peripheral effects upon the nervous system. It has been shown to alter the normal electroencephalogram producing high-voltage fast activity in doses of about 3 grains intravenously, and slow activity in anaesthetic doses (Brazier and Finesinger, 1945). Clinically, by mouth or injection, in adequate dosage sodium amytal produces drowsiness and sleep (Council on Pharmacy and Chemistry, 1931), and small doses intravenously have been described as producing increased communicativeness and feelings of well-being in normal subjects (Lindemann, 1932). In anxious subjects there is frequently an alleviation of anxiety (Sargant and Slater, 1954), and in neurotic subjects communicativeness and unrestrained emotional expression may reach the point of abreaction (Horsley, 1943; Ripley and Wolf, 1947 ; Mallinson, 1940). Abstinence from regular use of the drug may be associated with withdrawal symptoms which include insomnia, restlessness, epileptic seizures, and psychotic states, generally of a delirious type (Wikler, 1953). These phenomena have been interpreted as indicating that amytal depresses cerebral mechanisms, particularly those functions mediated by the cerebral cortex. But the influence of barbiturates on the nervous system has been differently interpreted according to the stage of anaesthesia obtained (Brazier, 1954).

Adrian (1941) has shown in a variety of experimental animals that dial and nembutal anaesthesia alters the cortical components of the electrical activity recorded from that structure, and reduces the tendency for afferent stimuli to produce excitation in appropriate parts of the cortex. It also reduces the tendency for such excitation, when it does occur, to spread into the neighbouring cortex.

Experiments of Masserman (1938) in the cat suggested that amytal depresses sympathetic and emotional mimetic activity resulting from faradic stimulation of the hypothalamus. It was suggested that this interference was at the level of the hypothalamus. Subsequently, Trethewie (1953) has shown that nembutal inhibits the output of adrenaline from the sympathetic nerve endings and from the adrenal medulla, and that this is a peripheral effect situated principally at the level of the autonomic ganglion cell. The interference with sympathetic nervous functions by amytal is probably sited peripherally at this level also.

Sodium amytal has been described as "deconditioning" subjects prone to anxiety in specific anxiety-provoking situations (Sargant and Slater, 1954), and it has been found to abolish conditioned fear responses in kittens (Bailey and Miller, 1952). The present authors (Franks and Laverty, 1955) have shown elsewhere that amytal administered intravenously tends to depress both the acquisition and the resistance to extinction of eyelid conditioned responses in dysthymic subjects. ("Dysthymic" is a term used by Eysenck (1947) to describe those introverted neurotics generally diagnosed as suffering from anxiety states, obsessive compulsions, or reactive depression.) In the same paper it has also been shown that amytal apparently increases extroversion, as measured by Guilford's questionnaire (Guilford, 1940).

The present paper, which must be regarded as a pilot study only, is concerned with more general aspects of behaviour and personality changes observed during and immediately after the conditioning experiment referred to above.

\section{Subjects}

Sixteen subjects suffering from neurotic illness and regarded as free from psychotic traits, organic brain damage, and subnormal intelligence were selected on the basis of their possessing personalities of a predominantly introverted type. This selection was made on the evidence provided by their case records, and an interview at which their cooperation in the investigation was invited. They were told that the purpose of the investigation was to discover whether a certain drug (whose name they were not told) would have a relaxing action upon them. Seven subjects were male, nine female. Ages ranged from 17 to 46 years. 


\section{Treatments}

To estimate the influence of the drug four types of treatment were employed : (A) A larger dose of sodium amytal ; (a) a smaller dose ; (P) a placebo injection of sterile water ; $(\mathrm{N})$ no injection.

The choice of these four treatments was arrived at as follows. It is well known to anaesthetists and other workers using drugs of the barbiturate series that there is a wide variation in the susceptibility of individuals to these drugs. For example, Goodman and Gilman (1941) conclude that "when barbiturates are injected intravenously it is difficult to judge in advance the amount to be given ... reliance cannot be placed on fixed doses based on age and weight ... individuals vary in their response".

The mental state may in some cases influence the dosage requirements. Manic patients can tolerate extremely high doses and patients suffering from organic brain damage appear to be rendered unconscious by smaller doses of amytal than psychiatric patients suffering from the functional psychoses and from psychoneuroses (Thorner, 1935). As has been suggested by Franks (1954) this may be explained in terms of Pavlov's concepts of cortical inhibition and excitation. Patients with brain injuries may be regarded as possessing more than the normal amount of inhibition and would therefore require less of a cortically inhibiting drug such as sodium amytal to induce an inhibitory phenomenon such as sleep. Intravenous doses of 1.5 grains of sodium amytal have been regarded as reducing nervous tension in neurotic subjects (Susselman, Feldman, and Barrera, 1946). Doses of up to $7 \frac{1}{2}$ grains intravenously have been used to obtain the state of drowsiness deemed most suitable for procuring abreaction (Mallinson, 1940).

Before selecting the dosage of sodium amytal for the present experiment some preliminary trials were carried out on the type of subject to be used. There appeared to be some positive relation between the degree of manifest anxiety and the dosage required for its relief, and a tendency for physically heavier patients to tolerate a larger dose without drowsiness. Two doses were selected, a larger dose (A) of $\frac{1}{2}$ grain per stone body weight, and a smaller dose (a), which was always 2 grains less than the larger as calculated for each subject. This gave a dosage range varying from 4 to 6 grains for the larger dose and from 2 to 4 grains for the smaller. It was expected that these differences in dosage might be reflected in the results obtained. Clinically these doses would seem to work satisfactorily; no subjects are made too drowsy to participate and yet all appeared clinically to be influenced by the drug.

Placebo (P) injections (10 ml. sterile water) were given intravenously in place of the drug in a quarter of the tests, and no injection (N) in a further quarter. It is unnecessary to stress the importance of using a placebo in such drug trials, except to say that comparison with an inert substance is particularly essential when drugs which may influence suggestibility are employed. Eysenck and Rees (1945) have shown that sodium amytal under certain conditions increases suggestibility and Lewis (1941) has called attention to the possible influence of suggestion in procuring therapeutic results barbiturate abreaction.

\section{Experimental Design}

Since there are four different treatments it would ha् been preferable if each subject were given all foor treatments so that full comparisons within each subject could be made. For administrative reasons each subjet could be seen only twice. This made the experimenal design a more complicated one. It is possible to construct a "balanced design" so that each subject receives to different treatments and yet all treatment combinations are covered by using only six subjects $(\mathrm{a}-\mathrm{a} ; \mathrm{A}-\mathrm{B}$; $\mathrm{A}-\mathrm{N} ; \mathbf{a}-\mathrm{P} ; \mathrm{a}-\mathrm{N} ; \mathbf{P}-\mathbf{N})$. However, since the order. $\mathrm{f}$ treatment may be important it is necessary to rep $\overline{\bar{a}}$ t each of these six combinations on a different subject in the reverse temporal order, e.g., N-A and A-T. The 12 patients were allocated to these 12 treatment combinations by reference to a table of random numbers.

In addition it was thought worth while at this pitot stage to investigate the consequences of giving the safte treatment upon both occasions. Therefore four subjecis, also selected at random from the initial 16, were tested with the treatment combinations $\mathbf{A}-\mathbf{A}, \mathbf{a}-\mathbf{a}, \mathbf{P}-\mathbf{P}$, a $\mathrm{N}-\mathrm{N}$. The interval between test and retest was five seven days.

\section{Procedure}

The subject was taken to a room adjacent $t \&$ the testing room and requested to rest on a couch for 3 few minutes while the injection was prepared. Sodium amytal, $7 \frac{1}{2}$ grains, was dissolved in $15 \mathrm{ml}$. of sterile \&ayer giving a solution containing $1 \mathrm{gr} . / 2 \mathrm{ml}$. The appro amount of the solution was injected intravenously right arm at a rate of 1 grain $(2 \mathrm{ml}$.) per minute. fer the needle was withdrawn the pulse was taken and the subject was requested to sit up. After three minutes he subject walked a few yards to the soundproof conditioning laboratory (Franks, 1955). Here he seated comfortably and fitted with the apparatus necessary for eyelid conditioning. This consisted of a paircof padded earphones, a pair of plain glass spectacles for deliverance of a mild (65 mm. of mercury) air puff and for housing a recording photo-electric cell. The subject was seated at a booth, so situated that his field of vision was confined largely to the walls of this booth.

The same procedure was adopted for the place. injection, except that sterile water was used. For the "no injection" treatment the subject was told to iest for approximately the same time as was normally taken up by the other treatment procedures. At all times evgry possible care was taken to ensure that the subject was given no indication of which treatment he had receiyed or was about to receive except in so far as he was naturatly aware that he was receiving no injection whatsoever. $D$

Seven minutes after the injection was terminated the conditioning procedure was begun. This followecha routine pattern (Franks, 1956) and lasted approximately 30 minutes. During this time a detailed clinical obser tion of the subject's behaviour was made by one of experimenters. Each subject was then questioned asto 
his subjective feelings and impressions immediately after the injection and during the conditioning and clinical behaviour study.

Finally the subject was asked to sort several questionnaire scales of Guilford (1940) and the Maudsley Medical Questionnaire. Included in the Guilford scales were scales $\mathbf{S}$ (social introversion), D (depression), C (cycloid disposition), and $\mathbf{R}$ (rhathymia). However, there is good evidence (Hildebrand, 1953) to suggest that $\mathrm{D}$ and $\mathrm{C}$ are largely measures of a personality factor of general neuroticism and $R$ is largely a measure of extroversion. It has been shown by Eysenck (1953) that neuroticism and introversion-extroversion are two mutually orthogonal dimensions of personality. Dysthymic neurotics have a high score on neuroticism and on the introverted end of the introversion-extroversion dimension ; hysteric and psychopathic neurotics have a high score on neuroticism and on the extroverted end of the introversion-extroversion dimension.) Unlike the standard procedure suggested by Guilford, each item was printed on a separate card. The subject was then instructed to "post" each card into one of three boxes marked "Yes", "?", and "No" respectively. The Maudsley Medical Questionnaire (M.M.Q.) is a scale of 58 items consisting of 40 " neurotic" items and 18 lie scale items. There is good evidence (Hildebrand, 1953 ; Eysenck, 1952) to suggest that, given adequate subject motivation, the M.M.Q. is a reasonably good measure of neuroticism. This scale was administered in a manner similar to the previous ones except that only two boxes were used labelled "True" and "False" respectively.

\section{Clinical Observations of Behaviour}

During the conditioning experiment the subject is seated quietly in a chair, the head supported by a padded head-rest, the arms lying in the lap, the feet resting on a footstool. The subject has been instructed that he has nothing to do except relax and look at a low-powered red light whenever it goes on. Under these conditions it might be expected that whatever movements occurred would be related to discomfort, anxiety, or tension experienced by the subject. Preliminary observations led us to expect three groups of movements to occur with some regularity. These were : (1) Movements of the general somatic musculature ; of the head or limbs, or shifting of the whole body. These were generally slow, stretching movements or simple shifts in posture commonly shown by people constrained to sit still for any length of time. In addition there were observed more rapid movements, foot-tapping and finger-tapping (in one case each), and a sudden jerk of the head in response to the air puff impinging on the eye. This latter movement usually occurred in response to the first two or three puffs only and disappeared thereafter. (2) Respiratory movements ; deep breathing (periodic hyperventilation), coughing, clearing the throat, yawning. (3) Movements of the mouth ; swallowing, wetting the lips.

The observer sat behind and to the right of the subject, who never appeared to be aware of being observed. In this position a profile of the subject, which included the mouth, neck, supraclavicular region, and arm and leg on the right side, was easily observed.

Under the somewhat constraining conditions of the experiment the movements observed were generally sufficiently isolated, definite, and infrequent to make the accurate recording of them both feasible and straightforward. Attention was focused on the areas (neck and supraclavicular) where breathing and swallowing were observed. It was the rule to find subjects drawing an occasional deep breath or sometimes audibly sighing during otherwise quiet breathing. Movements of the head, limbs of the right side, and general shifts of the whole body in the chair were recorded when they occurred. Frequently a sequence of deep breathing, swallowing, and general shifting was observed.

Observations were made for periods of four minutes followed by one minute's rest for the observer. All movements of the patient as described above were recorded during these four-minute periods. After five such periods the conditioning experiment was nearly ended and no further observations were recorded.

\section{Analysis of Data}

The analysis of variance technique was used, modified in the manner recommended by Cochran and Cox (1950). For each measure the average treatment effect is the straightforward average for each treatment. This has then to be adjusted to allow for the fact that any one person has only received two of the four possible treatments, the method of adjustment being that followed by Cochran and Cox. It is these adjusted treatment effects $(H)$ which are used for $t$ tests of significance whenever the analysis of variance yields a significant $F$ ratio. The appropriate error variance for the $t$ tests (Cochran and Cox, 1950) is given by $\frac{1}{2}$ (residual error variance in the analysis of variance).

The results for the four persons tested $\mathrm{A}-\mathrm{A}, \mathrm{a}-\mathrm{a}$, $\mathbf{P}-\mathbf{P}$, and $\mathrm{N}-\mathrm{N}$ were treated separately from the main data, the analysis being confined (since this is a pilot study) to a simple examination of the data. Finally the raw scores for the clinical behaviour measures were correlated.

\section{Results}

Movements. - As can be seen from an examination of Table $I$ the result of adjusting the treatment means is that sometimes the adjusted treatment mean $(\mathrm{H})$ is negative. Analysis of variance of each movement gives no significant $F$ ratios for the treatment effects with the exception of deep breathing where the treatment effect $F$ ratio is significant at the $1 \%$ level $(\mathrm{F}=34 \cdot 2$, d.f. $=3$ and 8). When $t$ tests are carried out on the differences between the adjusted deep breathing means for different treatments it is found that sodium amytal (A, a) significantly reduces the number of deep breaths $(\mathrm{P}<0.05 \%)$. There is no significant difference between the number of deep breaths produced with treatments $P$, i.e., using a placebo, and $N$, i.e., using no drug, which fail to reveal any 
TABLE I

AVERAGE NUMBER (ADJUSTED) OF MOVEMENTS FOR EACH TREATMENT USING ADJUSTED TREATMENT MEANS (H)

\begin{tabular}{|c|c|c|c|c|c|c|}
\hline \multicolumn{3}{|l|}{ Movement } & $\begin{array}{c}\text { Treat- } \\
\text { ment } \\
\mathbf{A}\end{array}$ & $\begin{array}{c}\begin{array}{c}\text { Treat- } \\
\text { ment } \\
\mathrm{a}\end{array} \\
1.63\end{array}$ & $\begin{array}{c}\begin{array}{c}\text { Treat- } \\
\text { ment } \\
\mathbf{P}\end{array} \\
1.88\end{array}$ & $\frac{\begin{array}{c}\text { Treat- } \\
\text { ment } \\
\mathbf{N}\end{array}}{1 \cdot 76}$ \\
\hline $\begin{array}{l}\text { Head } \\
\text { Arm on right side } \\
\text { Leg on right side } \\
\text { General shifting of } \\
\text { Cough } \\
\text { Deep breath.. } \\
\text { Swallowing .. } \\
\text { Mouth }\end{array}$ & $\begin{array}{l}\cdots \\
\cdots \\
\text { body } \\
\cdots \\
\therefore \\
\cdots\end{array}$ & $\begin{array}{l}\cdots \\
\cdots \\
\cdots \\
\cdots \\
\cdots \\
\cdots\end{array}$ & $\begin{array}{c}0.25 \\
0.16 \\
0.75 \\
-0.17 \\
-0.54 \\
-0.50 \\
0.83 \\
\text { Number } \\
\text { too lo }\end{array}$ & $\begin{array}{c}1.63 \\
0.79 \\
0.12 \\
1.84 \\
0.33 \\
2.00 \\
1.08 \\
\text { of rec } \\
\text { w for cor }\end{array}$ & $\begin{array}{r}1.88 \\
1.04 \\
1.25 \\
0.96 \\
1.96 \\
7.26 \\
7.84 \\
\text { orded mo } \\
\text { nsideratior }\end{array}$ & $\begin{array}{r}1.76 \\
1.17 \\
0.88 \\
1.21 \\
2.09 \\
6.76 \\
6.09 \\
\text { vements }\end{array}$ \\
\hline \multicolumn{2}{|c|}{ Total movements } & $\ldots$ & $1 \cdot 13$ & $7 \cdot 38$ & $23 \cdot 89$ & $20 \cdot 64$ \\
\hline
\end{tabular}

"suggestion effects" as far as deep breathing is concerned. The larger dose of amytal (A) produces significantly fewer deep breaths than the smaller dose (a) $(\mathrm{P}<2.5 \%)$.

Analysis of variance of the total number of movements yields a treatment effect $F$ ratio significant at the $5 \%$ level. $t$ Tests show that the total number of movements for the drug treatments is significantly less $(\mathrm{P}<1 \%)$ than the total number of movements when no drug is given. As before, no significant differences were found for the total number of movements for the two treatments $P$ and $\mathrm{N}$.

The movements of the four subjects given the same treatments at test and retest are approximately in agreement with these findings. Thus the average number of movements of all kinds for the two subjects receiving amytal ( $\mathrm{A}$ and $\mathrm{a}$ ) is 14 , and the average number of movements for the two subjects not receiving amytal (P and $\mathbf{N}$ ) is 29.

As far as possible, i.e., when the distribution of the data and the lack of zero numbers allowed, the Pearson product moment intercorrelations between the various movement scores were calculated (Table II).

TABLE II

INTERCORRELATIONS BETWEEN MOVEMENT MEASURES USING ADJUSTED TREATMENT MEANS (H)

\begin{tabular}{|c|c|c|c|c|c|c|c|}
\hline $\begin{array}{l}\text { Correla- } \\
\text { tion } \\
\text { Between }\end{array}$ & H.RA & H.RL & H.GS & RA.RL & RA.GS & RL.GS & DB.S \\
\hline$r$ & $0 \cdot 37$ & $\overline{0 \cdot 12}$ & 0.85 & 0.32 & 0.33 & 0.57 & 0.44 \\
\hline
\end{tabular}

Although only two of the above correlations are statistically significant (using a two-tailed test $\mathbf{r}$ must be 0.50 for significance at the $5 \%$ level) they are all positive and suggest some agreement between the various measures. Subjects who score high/low on one measure tend to score high/low on other measures.
The Personality Questionnaires.-Analysis variance failed to reveal any significant treatmer effects or tendencies for the measures of neuroticis used (Guilford's D and C scales and the M.M.Q. Neither is there any significant treatment $F$ ratio for the Lie scale. Also no consistent trends ares observable for any of these measures.

Table III gives the adjusted treatment means (倩 for the total number of cards put in the "Yes" bo and for the total number of cards put in the "?" box.

TABLE III

TOTAL NUMBER OF QUESTIONNAIRE ITEMS ANSWERES "YES" OR "?"

ADJUSTED TREAMENT MEANS (H)

\begin{tabular}{|c|c|c|c|c|}
\hline Answer & $\begin{array}{c}\text { Treatment } \\
\text { A }\end{array}$ & $\begin{array}{c}\text { Treatment } \\
\mathbf{a}\end{array}$ & $\underset{\mathbf{P}}{\text { Treatment }}$ & Treatment \\
\hline $\begin{array}{c}\text { Yes } \\
?\end{array}$ & $\begin{array}{r}124.6 \\
3.9\end{array}$ & $\begin{array}{r}120 \cdot 2 \\
6.0\end{array}$ & $\begin{array}{r}102 \cdot 7 \\
15 \cdot 3\end{array}$ & $\begin{array}{ll}99.3 & \overrightarrow{0} \\
13.9 & \end{array}$ \\
\hline
\end{tabular}

Analysis of variance shows that the test-retest $\stackrel{\omega}{\Phi}$ ratio is insignificant for both measures. The treatment effect $F$ ratio is significant at the $1 \%$ level for the number of cards answered "Yes" bu insignificant for the number of cards answered "?". t Tests show that, irrespective of which dose of sodium amytal is injected, the numbe cards answered "Yes" is significantly $(P<$ POP $)$ greater than when the $\mathbf{P}$ or $\mathbf{N}$ treatment is use There is no significant difference between ot he "Yes" scores for $\mathbf{P}$ and $\mathbf{N}$. There would also seem to be an insignificant but consistent tendencyôेf sodium amytal to reduce the number of căres answered "?". These findings are in agreemegt with the results obtained for the four subjects give the same test and retest treatment. Thus the average "Yes" score for subjects receiving amytal is 1 \% whereas the average "Yes" score for subjects n\&t receiving amytal is 107 . Similarly the average "? scores are 5 and 10 respectively.

Responses to Verbal Questions.-(1) All subject舁 were asked, " How did you feel after the injection? or " How did you feel ?", if treatment $\mathrm{N}$ was give

Some of the responses given in answer to these questions are as follows. (In evaluating the replies it should be remembered that for some of the subjects the question was being asked for the secon time, i.e., during the second session and that they had therefore received one of the four treatments at the first session.)

Subjects Receiving Larger Dose of Drug $(A)$

I felt better-the tight feeling in my stomach has gorfs I felt drowsy, the same as last time.

It's escape-very relaxed - as if I'd had a good drints Very sleepy.

I never felt so pleasantly dreamy in my life. 
Subjects Receiving Larger Dose of Drug $(A)$--cont.

I was drowsy-pleasant though-like being drunk.

A lovely feeling - slightly dizzy.

Why should I worry -I've had a row with my wifebut I don't care-it's all over.

Subjects Receiving Smaller Dose of Drug (a)

Felt rather sleepy-stopped worrying about anything. I feel good now.

I feel sleepy-in a dream almost.

A bit swimming-like one over the eight.

The fluttering in my stomach has gone-but it went to my head too-I was afraid someone would take advantage of me.

Eased my nerves - I feel quite composed.

Relaxed me like last time-what is it ?

Felt relaxed - sort of couldn't care less.

It's nice-but it's a little hard having to concentrate when you want to relax.

I feel as if I'd had a few beers-a happy feeling.

Subjects Receiving Placebo $(P)$

I'm not relaxed like I was last time-don't feel relaxed at all.

It was a bit of a strain-I didn't feel any different really.

Felt no difference-was worrying about possibility of getting evening appointments.

No effect-it didn't seem to work on me.

Couldn't keep my mind still.

Last time I was thinking about all different thingsthis time my mind was just a blank.

This time my left side went all stiff-I didn't feel happy like I did before.

I was worried if the effect would last-thought I might attack someone while I was drugged. Felt upset about that.

Subjects Receiving No Injection $(N)$

This time I felt restless, last time I didn't mind, this time I felt like blinking more.

I was all right - uncomfortable having to sit still so long.

All right-not sorry it's the last one.

I don't recall feeling any different from usual.

I'm afraid I wasn't relaxed enough for you.

I was thinking too much-it was like the 9 o'clock news.

Not like last time-hardly remember that-I felt the puffs more this time.

It was better than I expected.

In general, subjects receiving sodium amytal tended to report pleasant feelings of relaxation, drowsiness, relief from worry or somatic discomfort, pleasant and happy feelings, slight dizziness, and difficulty in concentration. Subjects receiving the placebo injection or no injection tended to report no change in their feelings and commented upon their general feelings of discomfort.

(2) All subjects were asked, "How did the air puff feel?" Subjects receiving amytal (A or a) tended to report the air puff stimulus as bearable (11 subjects), not unpleasant (12 subjects), much less unpleasant than last time, less strong than last time, negligible (each one subject).

Subjects receiving the placebo injection $(P)$ tended to report the air puff stimulus as slightly stronger than before, " made you jump this time, not at all before", slightly unpleasant. Only five subjects reported the air puff as being bearable.

Subjects receiving no injection $(\mathrm{N})$ reported the air puff stimulus as being stronger than before, uncomfortable, rather unpleasant. Only four subjects reported the air puff as being bearable or " not bad".

(3) All subjects were asked, "Was it hard to sit still ?" Subjects receiving amytal (A or a) answered "No" (14 subjects), "Yes" (one subject), "a little" (one subject). Of the subjects receiving a placebo or no injection ( $\mathrm{P}$ or $\mathrm{N})$, only eight answered "No" and six answered "Yes".

(4) All subjects were asked, "Did it seem a very long time that you sat there?" (actually about half an hour). Subjects receiving amytal (A or a) replied "No" in 10 cases. Other answers were "very quick, really ", " only a few minutes", " 10 minutes or so ", " over very quickly ", " not long ". No one answered "Yes".

Subjects receiving a placebo or no injection ( $P$ or $\mathrm{N}$ ) reported "Yes" in six cases. Nine subjects replied "No".

\section{Discussion}

Movements.-The number of movements observed clinically under treatment $\mathbf{P}$ (placebo) was never significantly different from that observed under treatment $\mathrm{N}$ (no injection), neither were any trends apparent. In those cases where drug treatments were employed the total number of movements was significantly fewer than when no drugs were used.

Assuming that changes associated with the administration of the drug (and absent when a placebo was given) can be attributed to its action the following conclusions are permissible.

Sodium amytal, as administered in the present study significantly reduces the total number of movements observed. (2) Sodium amytal significantly reduces deep breathing (periodic hyperventilation). This reduction is very marked and in some cases the deep breathing was abolished completely during the period of observation. (3) Although the differences are not significant apart from deep breathing, for each of the eight individual movements the two drug treatments seem to produce fewer movements than the two treatments not using drugs (with one exception). (4) The increase in dose of 2 grains from the smaller (a) to the larger (A) dose of amytal produces a significant further reduction in movement only in the case of deep breathing.

A tentative interpretation of these findings required consideration of other information. Brazier (1954), in a detailed review of the effects of 
barbiturates on the nervous system, suggested that the first stage of barbiturate anaesthesia (before sleep is induced) is attributable to the action of these drugs on the cerebral cortex alone. She relates effects found in deeper anaesthesia to the influences of the drug on the sub-cortical nonspecific sensory systems.

" High-voltage fast activity is characteristic of this first stage of barbiturate anaesthesia, and there appears to be differential activity on the part of different cortical areas. Fast waves of the orbital cortex appear to be independent of those of the cortex at the convexity. It seems reasonable to deduce that barbiturate at this stage acts directly on the cortical cells, and that the cortex is not being paced into any kind of synchrony from below, although the drug may well be having the same type of independent effect on neuronal groups subcortically."

The effect of the dosage of sodium amytal used in the present study corresponds to the first stage of barbiturate anaesthesia. The subject's behaviour is affected but sleep is not induced, and there is practically a normal degree of control of voluntary movements. The dosage employed ( 2 to 6 grains) is that at which fast activity could be expected in the E.E.G.

The reduction of movements may be understood as a failure of sensory stimuli to produce a spread of electrical activity through the cortex, even when producing a sharp localized cortical response, as described by Adrian (1941) in a variety of experimental animals under dial anaesthesia.

Periodic hyperventilation in neurotics has been regarded as of cortical origin since it disappears in sleep (Mudd, 1925). In the present study it has been found that such respiratory movements appear to be reduced to a greater extent by sodium amytal than those movements affecting the general muscular posture of the head, body, and limbs. Now respiratory movements are represented on the orbital surface of the cortex and muscular movements on the convexity surface. Therefore the differential influence of sodium amytal on these two types of movements may be interpreted as a selective effect of the drug, depressing the function relating to the orbital surface to a greater extent than those related to the convexity surface. The differences in E.E.G. readings from orbital and convexity surfaces of the brain obtained by Brazier following barbiturate administrations may also be interpreted in this manner. The clinical observation of Sargant and Slater (1954) that amytal is more effective in reducing anxiety than in reducing motor excitement could also be accounted for in terms of the differential action of the drug on different cortical areas.

Questionnaires.-The number of affirmative responses to the questionnaires was significantly increased when sodium amytal was used as treatment and the number of doubtful responses was reduced, although not significantly. Thas tendency to say "Yes" more often and "?" less often under the influence of amytal was expected. $\bar{\Phi} t$ agrees with the general clinical impressions of subjects influenced by the drug ; they appear to less hesitant, cautious, and indecisive and mo positive in stating their opinions.

The finding that sodium amytal failed to produce any changes on any of the questionnaire measures of neuroticism is of interest. Clinically amytal क्षs often used for the reduction of manifest anxiewy and there is no doubt that it is effective for thes purpose ; it would seem that sodium amytal reduces sympathetic adrenal hyperactivity. Based on a series of factor analytic studies by Wenger (1941, 1942a, 1942b, 1948), Eysenck (1954) has suggested that autonomic imbalance is the physiological concomitant of the dimension of neuroticism a that neuroticism can be described physiologically terms of sympathetic overactivity. If this is so then one would expect that sodium amytal woutd significantly reduce the scores on tests which measure neuroticism. The fact that such reducto $\overrightarrow{0 s}$ were not evident in the present study requires fughet confirmation. It may be that the drug has seconeapy effects such as drowsiness which prevent ${ }^{0}$ the reduction in the neuroticism scores from becorgi apparent. It may also be possible that an increased tendency to reply "Yes" while under the influenge amytal obscures the expected result.

The finding that amytal apparently increases the extroversion of the subjects, as measured by Guitford's R scale, has been discussed elsewhere (Franfs and Laverty, 1955). This effect may also be in pof spurious in that it is related to the increased tendengy to answer the questions in the "Yes" direction. Ht may be that answering "Yes" more often has a greater positive influence on the $R$ scale than on any other scale. The method of scoring used in the prese्तुt study unfortunately prevents this possibility from being examined any further.) On the other hand the general unreflective nature of the drugged subject?s behaviour resembles that observed in extroverted subjects and supports the hypothesis that amytal does increase extroversion. Whatever the esplanation of the increase in $R$ scores of those subjects who had received amytal it is of great interest that a drug can influence the responses to questionnaire highly reliable under normal cond tions of attitudes and opinions even when the tesretest interval is as short as five to seven days.

Verbal Question.-Pleasant mood changes, oftep associated with drowsiness and relief of anxiety, 
were reported by subjects receiving the drug, whereas subjects who did not receive the drug reported a variety of feelings mostly indicative of some strain or discomfort. No marked or consistent changes were described by the subjects receiving placebo injections. Subjects receiving the drug consistently commented upon their relief from anxiety symptoms. It is of interest that this verbal expression of reduced anxiety did not seem to be reflected in their answers to the written questionnaires.

The subjects receiving the drug also reported less discomfort, less difficulty in sitting still, and that the air puffs were less irritating. This is in agreement with the finding that dial prevents the spread of afferent stimulation through the cortex in the receiving areas (Adrian, 1941).

The subjects given the drug tended to report that the experiment did not take a long time and that it was soon over, whereas many of the subjects who were not given the drug reported that the experiment took a long time. This is in agreement with the finding of Lindemann (1932) that normal subjects tend to underestimate time when under the influence of sodium amytal.

\section{Summary}

Sixteen introverted neurotic patients were investigated, each subject being seen twice, at an interval of about six days. Four different treatments were used, consisting of a larger dose of intravenous sodium amytal, a smaller dose, a placebo injection, and nothing. These four treatments were incorporated into the experimental design in such a way that no two subjects received the same treatment combinations. At each session the subject was given the appropriate treatment, observed for half an hour while sitting in a relaxed position in a sound-proof room, and his body movements were carefully recorded. The subject was then asked to answer certain personality questionnaires measuring introversion-extroversion and neuroticism.

The major findings were that :

(1) Sodium amytal significantly reduced the number of movements observed, in particular deep breathing.

(2) The placebo injections failed to produce any results which were significantly different from those when no injections at all were given.

(3) Sodium amytal produced no changes in the subjects' " neuroticism" scores as measured by the personality questionnaires but significantly increased their " extroversion" scores.

(4) Sodium amytal significantly increased the number of questionnaire items to which the subjects replied Yes.

(5) Sodium amytal produced reports of increased relaxation, drowsiness, relief from worry or somatic discomfort, etc.

(6) Those subjects who had received sodium amytal tended to find it easier to sit still during the experiment and tended also to underestimate the passage of time.

The implications of these findings were discussed in terms of those obtained by other experimenters in the field.

\section{REFERENCES}

Adrian, E. D. (1941). J. Physiol. (Lond.), 100, 159.

Bailey, C. J., and Miller, N. E. (1952). J. comp. physiol. Psychol.,

Brazier, M. A. B. (1954). In Brain Mechanisms and Consciousness : A Symposium organized by the Council for International Organizations of the Medical Sciences, p. 163. Blackwell,

London.
and Finesinger, J. E. (1945). Arch. Neurol. Psychiat. (Chicago), 53,51 .

Cochran, W. G., and Cox, Gertrude, M. (1950). Experimental Designs. Wiley, New York.

Council on Pharmacy and Chemistry (1931). J. Amer. med. Ass., 97, 1886.

Eysenck, H. J. (1947). Dimensions of Personality. Routledge \& Kegan Paul, London.

1952). The Scientific Study of Personality. Routledge \&

Kegan Paul, London.
(1953). The Structure of Human Personality. Methuen, London.

(1954). The Structure of Human Personality. Methuen, London. paper. London.

- and Rees, W. L. (1945). J. ment. Sci., 91, 301.

Franks, C. M. (1954). An Experimental Study of Conditioning as Related to Mental Abnormality. Ph.D. Thesis. University of London.

(1955). Nature (Lond.), 175, 984.

(1955). Nature (Lond.), 175, 984.

-(1956). J. abnorm. soc. Psychol., 52, 143.

Goodman, L., and Gilman, A. (1941). The Pharmacological Basis of Therapeutics. The Macmillan Co., New York.

Guilford, J. P. (1940). An Inventory of Factors $S T D C R$. Privately printed. Beverly Hills, Calif.

Hildebrand, H. P. (1953). A Factorial Study of Introversion-Extraversion by means of Objective Tests. Ph.D. Thesis. University of London.

Horsley, J. S. (1943). Narco-analysis. Oxford University Press, London.

Lewis, A. (1941). In Medical Annual, 1941, Mental Disturbance of War. Simpkin, Marshall, London.

Lindemann, E. (1932). Amer. J. Psychiat., 88, 1083.

Mallinson, W. P. (1940). J. roy. nav. med. Serv., 26, 281

Mallinson, W. P. (1940). J. roy. nav. med. Serv., 26, 281. 1250 .

Mudd, S. G. (1925). Boston med. surg. J., 193, 349.

Ripley, H. S., and Wolf, S. (1947). Psychosom. Med., 9, 260.

Sargant, W., and Slater, E. (1954). An Introduction to Physical Methods of Treatment in Psychiatry, 3rd ed. Livingstone, Edinburgh and London.

Susselman, S., Feldman, F., and Barrera, S. E. (1946). Arch. Neurol. Psychiat. (Chicago), 56, 567.

Thorner, M. W. (1935). J. nerv. ment. Dis., 81, 161

Trethewie, E. R. (1953). Med. J. Aust., 1, 100.

Wenger, M. A. (1941). Psychosom. Med., 3, 427.

- (1942a). Ibid., 4, 94.

(1942b). Hum. Biol., 14, 69.

(1948). Comp. Psychol. Monogr., 19, No. 4

Wikler, A. (1953). Res. Publ. Ass. nerv. ment. Dis., 32, 269. 